village life he is likely to push ahead with his own task in isolation. This memorandum, which has been sent to all African Governments, has drawn attention to the situation, and the next steps in dealing with it must be made by those on the spot. (Communicated by Miss B. D. Gisson.)

\title{
La protection des arts et métiers indigènes au Congo Belge.
}

Les lecteurs d'A frica apprendront avec intérêt qu'en présence de la décadence de l'art africain, le gouvernement colonial belge a témoigné son vif intérêt pour les diverses manifestations artistiques des populations congolaises en instituant dans la métropole une 'Commission pour la protection des arts et métiers indigènes' ayant pour mission 'd'étudier et de rechercher tout ce qui peut contribuer à leur sauvegarde, à leur conservation, à leur rénovation et à leur progrès'. Parallèlement à cette institution, il s'est formé à Léopoldville pour tout le Congo Belge et le Ruanda-Urundi une association sans but lucratif, désignée sous le nom 'Les Amis de l'Art Indigène' et placée sous la présidence d'honneur de $\mathrm{M}$. le Gouverneur Général de la colonie. 'L'association a pour but essentiel de protéger et de favoriser l'art et les métiers indigènes, dans leurs artisans et dans leurs réalisations ethnographiques et folkloriques originales, afin de sauvegarder voire d'enrichir le patrimoine artistique spécifiquement congolais. A ces fins, elle se propose de grouper toutes les bonnes volontés, de téunir les moyens indispensables et de susciter toutes actions morales et matérielles. Elle contribuera à l'établissement d'ateliers spécialisés, à la création de musées locaux, au développement des échanges entre les indigènes et les diverses régions du Congo, à la participation aux expositions universelles métropolitaines, à l'organisation de débouchés éventuels, au classement méthodique de la documentation appropriée; et toutes relations utiles seront nouées et développées avec les groupements et organęs intéressés de Belgique et d'ailleurs.'

On ne peut certes qu'applaudir à ces initiatives. En s'attachant à sauvegarder le trésor artistique africain, elles témoignent non seulement de la haute importance accordée aux valeurs spirituelles, elles illustrent aussi d'une façon évidente la digne préoccupation de conserver au sein de la société congolaise toutes les richesses et toutes les virtualités appelées à contribuer au développement ultérieur de la production artistique autochtone.

Sur le terrain des réalisations pratiques cependant la plus grande prudence s'impose. Il ne nous paraît pas inopportun de souligner que des traditions techniques même séculaires ne peuvent à elles seules suffire à assurer la continuité de l'art nègre. 'L'art n'est vraiment de l'art, a écrit Maurice Delafosse, que s'il correspond dans son expression comme dans son inspiration à la civilisation dont il est le produit pour ainsi dire sublimé.' Or, à l'heure actuelle la société indigène se modifie profondément. De jour en jour, elle acquiert avec des cadres nouveaux une âme nouvelle. L'art indigène lui-même ne peut échapper à ce renouveau. Ce serait contraire au progrès 
de vouloir perpétuer les aspects caractéristiques de l'art nègre en liant la conception esthétique de ceux qui se sont détachés du passé traditionnel, à des formes, des couleurs, des motifs, des sons, des gestes, qui précisément sont, sur le terrain artistique, l'expression d'une mentalité désormais disparue.

Quant aux métiers indigènes proprement dits, on ne perdra de vue impunément que les nouvelles conditions de vie entraînent inévitablement la décadence du travail de l'osier, des fibres textiles, des peaux, de l'argile, du bois, de l'ivoire, du fer, du cuivre. En ces différents domaines, l'appauvrissement se poursuit fatalement chaque jour davantage. Aussi est-il de toute nécessité de conserver autant que possible tout ce que les arts et les métiers indigènes possèdent d'essentiellement vital pour l'avenir. Tel est le cas sans doute de la tradition décorative.

En attendant que la société indigène soit assez évoluée pour rénover ellemême son art, ce rôle de conservation, tout limité qu'il puisse paraître, nous semble fondamental. Il est en effet extrêmement délicat pour le colonisateur d'intervenir plus tôt d'une façon directe et active. La création d'ateliers spécialisés par exemple ne peut avoir qu'un succès fort douteux. A part le fait qu'ils ne se conçoivent guère qu'en vue de perfectionner les procédés coutumiers, il faut encore se demander si les perfectionnements dont ils sont susceptibles les mettront à même de concurrencer efficacement la superiorité de l'outillage et des productions européens. Dès lors, on aura non seulement rien changé aux données du problème, on aura encore couru le risque d'avoir amené des gens, qui nous avaient donné confiance, dans une situation sans issue. (Communication de $M$. le Professeur N. DE ClEENE.)

\section{Vernacular Periodicals, No 18, Dikalo (Journal des Chrétiens de langue Douala. Edité par la Mission protestante française). Douala et Ndoungué, Caméroun.}

La tribu des Douala n'est pas extrêmement nombreuse, mais pourtant sa langue est parlée. ou tout au moins comprise par la plupart des indigènes habitant la partie sud-ouest du Caméroun. C'est cette langue qu'emploie la Société des Missions évangéliques de Paris (Mission protestante française) dans quatre de ses six districts missionnaires de ce pays.

Depuis plusieurs années, cette Société publie en douala un petit journal qui s'appela Ngengeti (' l'Étoile') avant de devenir Dikalo ('Proclamation, message'). D'abord imprimé, ce bulletin ne fut ensuite que polycopié pendant un certain temps; enfin l'installation d'une petite imprimerie à la station de Ndoungué, vient de lui permettre de prendre un nouvel essor.

Cette publication est avant tout destinée aux catéchistes et moniteurs de la mission, mais elle est également envoyée à certains abonnés, dont le nombre augmente très sensiblement en ce moment. Le numéro de mai et juin 1934 a été expédié à 500 catéchistes ou autres employés de la mission et à plus de 700 